\title{
USO DO MENTIMETER COMO METODOLOGIA ATIVA VIRTUAL NO CURSO DE GESTÃO AMBIENTAL DA FACULDADE ÚNICA DE IPATINGA
}

\author{
Ronald Assis Fonseca ${ }^{a}$ \\ Clélio Rodrigo Paiva Rafael ${ }^{\text {b }}$ \\ Emerson Francisco Victor ${ }^{\mathrm{C}}$ \\ Núbia Cristina Geraldo dos Santos ${ }^{c}$ \\ Amanda Xavier de Oliveirac \\ Cleiciane Ferreira da Silva ${ }^{c}$
}

a Coordenador do curso de Gestão Ambiental, Faculdade Única de Ipatinga. Rua Salermo, nº 299, Bethânia - CEP 35.164-777 - Ipatinga/MG

b Docente do curso de Gestão Ambiental, Faculdade Única de Ipatinga. Rua Salermo, n 299, Bethânia - CEP 35.164777 - Ipatinga/MG

c Discente do curso de Gestão Ambiental, Faculdade Única de Ipatinga. Rua Salermo, n 299, Bethânia - CEP 35.164-777 - Ipatinga/MG

\section{RESUMO}

Os avanços na área de ensino e educação estão em evidência nos últimos anos com o crescimento de metodologias ativas, tecnologias e práticas pedagógicas capazes de potencializar o ensino e aprendizagem do aluno como protagonista do conhecimento. No cenário de pandemia, ocasionado pelo Coronavírus (COVID-19) as TDIC's (Tecnologias Digitais de Comunicação e Informação) se tornaram uma solução para atividades virtuais de aprendizagem. Neste sentido, este trabalho visa apresentar o Mentimeter como metodologia ativa no ensino remoto para os alunos ingressantes do curso de Gestão Ambiental da Faculdade Única de Ipatinga na modalidade Ead como ferramenta capaz de promover a participação e interação do aluno. Através do "Momento com o Coordenador", foi possível identificar características sociodemográficas (sexo e estado) e os motivos pelos quais os alunos ingressaram no curso. O uso do Mentimeter permitiu a participação dos alunos que receberam um link de preenchimento automático, cujas respostas apareciam simultaneamente na tela de apresentação criando uma interação durante a aula. Esta plataforma pode ser utilizada para atividades diversas e neste trabalho contribuiu com a participação dinâmica e interativa dos alunos permitindo conhecer as características do público-alvo e nortear outras estratégias que garantam um ensino de qualidade e satisfação do aluno.

Palavras-chave: Ensino; Participação; Metodologia Ativa.

*Autor correspondente: Ronald Assis Fonseca, Mestre em Agroecologia, Rua San Diego n 325, Bethânia - CEP 35.164-777 - Ipatinga/MG Telefone de contato; ronald.ufv@hotmail.com 


\section{INTRODUÇÃO}

Os avanços e as inovações na área de ensino e educação vêm crescendo gradativamente nos últimos anos caracterizado pelo uso de tecnologias e práticas pedagógicas capazes de potencializar a participação efetiva do aluno, tornando-o como protagonista do conhecimento, participativo, colaborativo, inclusivo e socialmente justo (GIROTO et al., 2012). Neste cenário, o uso de tecnologias de informação e comunicação (TIC) tem se alavancado com a melhora educativa, favorecendo a transformação dos métodos de ensino tradicionais em novos modelos que permitem desenvolver uma aprendizagem ativa e colaborativa durante as aulas (LOPEZ et al., 2018).

O contexto de pandemia fez com o que o Conselho Nacional de Educação (CNE) emitisse um parecer referente à substituição das aulas presenciais para 0 formato não presencial nas instituições educacionais, e a adoção do trabalho remoto como uma solução emergencial e realizada por meio de metodologias ativas, como as Tecnologias Digitais de Informação e Comunicação (TDIC's), que são alternativas para o sistema de ensino não parar totalmente. Segundo o CNE, o uso das TDIC's possibilitaria a produção e disponibilização de materiais didáticos bem como, a promoção de encontros virtuais de ensino e aprendizagem entre professor e alunos (SCHNEIDER et al., 2020).

Essas metodologias ativas ganharam grande destaque nas instituições devido a necessidade do ensino remoto ocasionado pela pandemia de Coronavírus (COVID19) o que trouxe um cenário desafiador para docentes, discentes e para gestão escolar de modo geral, contribuindo para que as metodologias ativas de informação e comunicação, bem como os instrumentos pedagógicos, fossem adaptados para o ensino a distância (EAD), corroborando ainda mais com 0 crescente desenvolvimento destes instrumentos nos últimos anos. Essas ferramentas online deixaram de ser opção e passaram a ser a solução para a continuidade do ensino e educação durante a pandemia.
Segundo Santos e Silva (2009) os encontros virtuais são promovidos a partir de atividades síncronas e assíncronas no ambiente online de aprendizagem. Com elas, é possível a produção e o compartilhamento de conteúdo em diferentes formatos e linguagens e com isso, promover a interação entre os interlocutores (SANTOS; SILVA, 2009).

Porém, é importante que o docente ou as instituições, busquem meios, instrumentos, ferramentas, capazes de promover a participação do aluno, que de fato, mesmo que a distância, seja capaz de construir o seu conhecimento com base nas aulas e que o mesmo se sinta parte da aula, ator principal do aprendizado e não apenas um ouvinte. Se a modalidade a distância descaracteriza o contato social, a participação e a interação entre os alunos, existem metodologias ativas chamadas de TDIC's, capazes de oportunizar a dinâmica, a motivação, a prática e a participação do aluno, cada um em sua residência.

Buscando a participação e a motivação do aluno no curso de Gestão Ambiental da Faculdade Única de Ipatinga na modalidade a distância, este trabalho busca apresentar o uso da plataforma Mentimeter como metodologia ativa da TDIC's aplicada durante o "Momento com o Coordenador" que ocorre quinzenalmente para apresentar o curso, conhecer $o$ perfil $e$ as características sociodemográficas dos alunos. O Mentimeter possibilita a elaboração de apresentações interativas e em tempo real através de perguntas que resultam em gráficos, nuvem de palavras e outras representações lúdicas de fácil compreensão pelo leitor. A plataforma promove um ensino sistemático ativo, ou seja, focado no aluno, motivos esses que foram determinantes para seleção desta plataforma para a pesquisa.

O ensino a distância permite a participação de um público-alvo multidiverso, de regiões, características, níveis de ensino, acesso à informação diferentes. Por este motivo, é importante conhecer o perfil do aluno, e o Mentimeter foi capaz de promover a participação e a interação dos alunos, gerando 
ainda resultados sobre as características do público-alvo.

\section{MATERIAL E MÉTODOS}

\subsection{Plataforma Mentimeter}

Os alunos do Curso de Gestão Ambiental da Faculdade Única ingressam em fluxo contínuo no curso, o que necessita de um momento com o coordenador do curso, realizado na plataforma do Google Meet, em dias e horários pré-agendados para dar as boas-vindas, passar informações sobre o curso, bem como promover a interação entre os alunos que são de regiões e características diferentes.

Com a necessidade de oportunizar um momento online com alunos, que gere interação, motivação e dinamismo entre os alunos, foi pensado no uso de TDIC's para potencializar a participação do aluno, mostrando que o mesmo deve ser protagonista do processo de ensino aprendizagem e não apenas um ouvinte como nas metodologias tradicionais de ensino (LEITE, 2018).

Para diagnosticar o público-alvo, bem como conhecer suas expectativas e permitir a participação do aluno durante o encontro online, foi utilizado o Mentimeter (TDIC's) que é uma plataforma que foi criada em 2004, na Suécia, por Johnny Warström como resposta a reuniões improdutivas. A plataforma também se dedica à colaboração online no âmbito educacional, permitindo que os alunos respondam às perguntas anonimamente durante a aula, ampliando a participação (JUNIOR, 2020).

O Mentimeter permite que os usuários compartilhem conhecimento e feedback em tempo real no smartphone ou em outros dispositivos (tablet, notebook ou PC - personal computere). O compartilhamento inclui apresentações, pesquisas ou sessões de brainstorming em aulas, reuniões, encontros, conferências e outras atividades em grupo (JUNIOR, 2020).

Assim, durante o "momento com 0 coordenador" o professor após dar as boasvindas e apresentar o curso, explicou sobre o uso da plataforma Mentimeter e gerou links enviados para os alunos no chat do Google Meet e no grupo da turma no WhatsApp, onde cada link era referente a uma pergunta/ informação que o aluno deveria responder e após enviar, as respostas anônimas dos participantes apareceram de forma simultânea na tela compartilhada para os discentes.

Para gerar o link de preenchimento pelos alunos é necessário acessar o site do Mentimeter, cadastrar-se e criar uma apresentação. Nesta apresentação é possível escolher diversas ferramentas como gráficos, tabelas, enquetes, nuvem de palavras (word cloud), dentre outros. Após escolher, basta inserir a pergunta, selecionar a quantidade de respostas e enviar o link, obtendo o mesmo no menu "share" (compartilhar). É necessário inserir o link de respostas como suplemento no slide de apresentação e o outro link (de perguntas) ao aluno, que ao preencher, aparecerá simultaneamente na tela de apresentação.

\subsection{Etapas utilizadas no Mentimeter}

As etapas e procedimentos utilizadas no Mentimeter neste trabalho estão descritas abaixo:

1 - Realização do cadastro na plataforma: nesta etapa o professor acessou o site da plataforma (www.mentimeter.com) e selecionou o menu "Sign-up", localizado no canto esquerdo superior. Ao selecionar o menu de inscrição o professor foi redirecionado a uma página para preencher um formulário com seus dados pessoais como: nome, e-mail e como pretende utilizar a plataforma.

2 - Conexão a plataforma: tendo posse de uma conta no Mentimeter, o utilizador selecionou o menu "Login", encontrado ao lado do menu de inscrição, e forneceu o e-mail e a senha que foi cadastrado na plataforma

3 - Criação da apresentação: já conectado a plataforma, foi possível a elaboração de apresentações, e ainda editar projetos pré-existentes. Para criação de uma nova apresentação foi preciso selecionar o menu "+New presentation", posicionado na parte inferior da página, de maneira 
centralizada. Então, foi fornecido o nome da apresentação e em seguida a página foi redirecionada para elaboração do projeto.

4 - Seleção e configurar ação da ferramenta desejada: em continuidade a elaboração da apresentação selecionou-se a ferramenta utilizada. As ferramentas são dispostas dentro do menu "Type", organizadas em blocos verticais, na lateral esquerda da página. Os primeiros recursos mostrados são os dos submenus "Popular question types", "Quiz Competition" e o "Content slides". Finalizada a escolha da ferramenta a ser utilizada, configurou-se esta ferramenta. Para isso, foram preenchidas lacunas padronizadas individualmente para cada tipo de ferramenta. Como exemplificação, para utilização da ferramenta "Word Cloud", nuvem de palavras, foi pedido os dados: o questionamento; o número máximo de respostas por participante, em uma mesma entrada; uma imagem de fundo, caso desejado; e por fim, habilitar a opção de permitir que os participantes respondam várias vezes.

5 - Compartilhando as perguntas e respostas: completada a apresentação, podese então promover a interação com os participantes. Essa interação aconteceu através da resposta para os questionamentos feitos, em que os resultados geraram ilustrações de acordo com o tipo de ferramenta utilizada. Para que isso o professor selecionou o menu "Share", no canto superior esquerdo em que deu acesso a duas caixas, sendo um referente ao acesso dos participantes aos questionamentos e a outra para partilhar os resultados. As respostas podiam ser fornecidas através de um link em formato htlm HyperText Markup LanguageHyperText Markup Language e QR- code, ou ainda por meio do preenchimento da barra de códigos presente na página inicial do site, com o código disposto na caixa de participação. Já a divulgação dos resultados poderia ser feita através do fornecimento do link direto ou com inserção desse na apresentação de powerpoint ou em outro software compatível.

De maneira resumida, o fluxograma (Figura 1) a seguir ilustra a sequência a ser seguida das etapas abordadas anteriormente.

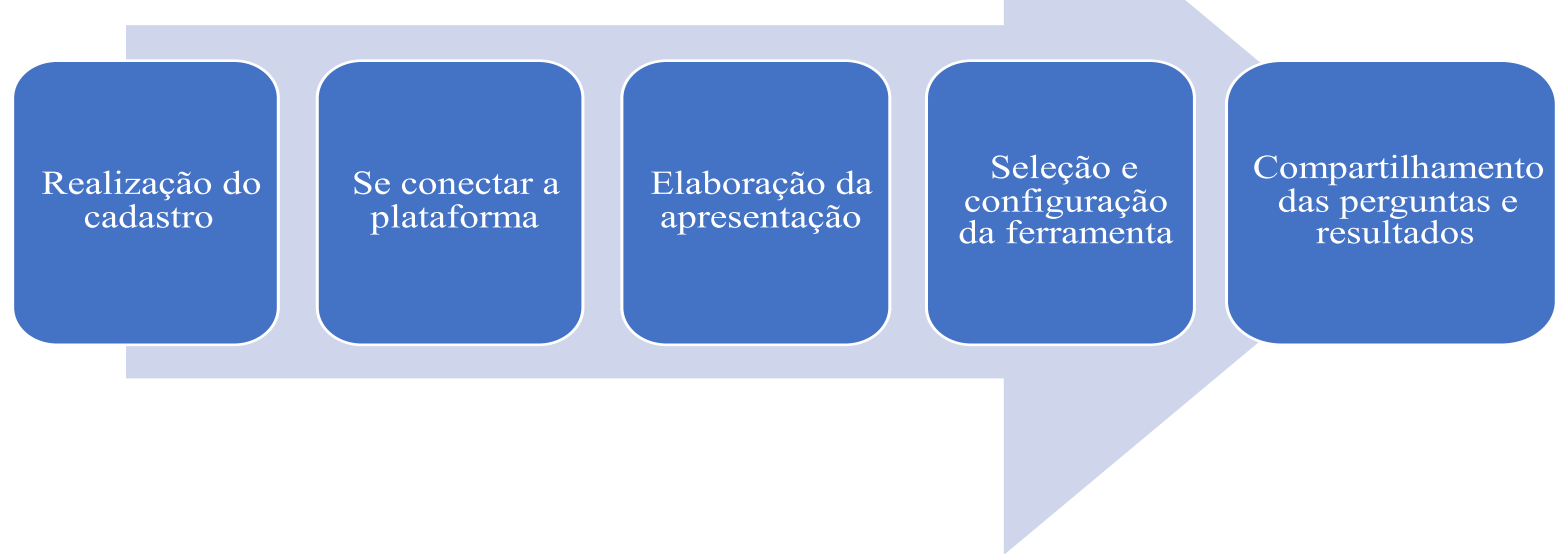

Figura 1: Fluxograma de acesso a plataforma e uso do Mentimeter. Fonte: Autores 2021.

\section{RESULTADOS}

Por se tratar de um momento para os alunos ingressantes no curso de fluxo contínuo de Gestão Ambiental, o número de alunos participantes não é grande, porém não representa o número total de alunos do curso, apenas os ingressantes daquele mês.
Neste sentido, 18 alunos participaram do momento com o coordenador e puderam participar da atividade. O primeiro link enviado para os alunos pelo chat do Google Meet e pelo grupo do WhatsApp, pedia apenas para preencher o sexo do ingressante: masculino e feminino e o recurso utilizado para representar os resultados foi através de gráfico (Figura 2). De forma geral, o gráfico foi organizado em 
posições decimais em que a alternativa que obteve mais respostas ficou na posição superior, ou seja, ocupando a primeira posição (1st) e a segunda opção consequentemente ocupou a segunda posição (2nd), como visto na Figura 2.

\section{Ranking}
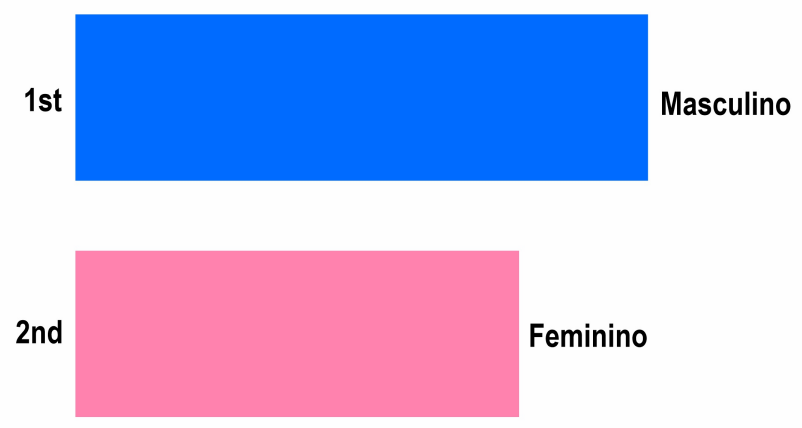

Figura 2: Gráfico resultante da participação dos alunos no momento com o coordena-dor utilizando o Mentimeter. Fonte: Autores 2021.

Este dado pode ser utilizado para analisar a preferência em relação a homens e mulheres que ingressam no curso de Gestão Ambiental, mostrando que o público é bem homogêneo, diferentes de alguns cursos no Brasil. De Moraes et al., (2018) encontraram homogeneidade entre os ingressantes de Gestão Ambiental da Universidade de Mato Grosso do Sul quanto ao sexo, tendo, porém, um número um pouco maior $(57 \%)$ de mulheres.

O segundo link enviado aos alunos perguntava qual o estado que este reside. Foi utilizado o recurso de Word Cloud (Nuvem de palavras) (Figura 3). Este dado é importante para mostrar como o cenário do ensino a distância é capaz de atingir públicos diversos, com culturas diversas promovendo uma troca mútua de saberes e experiências e o conhecimento de outras regiões de um país de proporções continentais como o Brasil, contribuindo com a interação entre alunos de um mesmo curso, mas de regiões tão distintas.

\section{Qual o seu estado?}

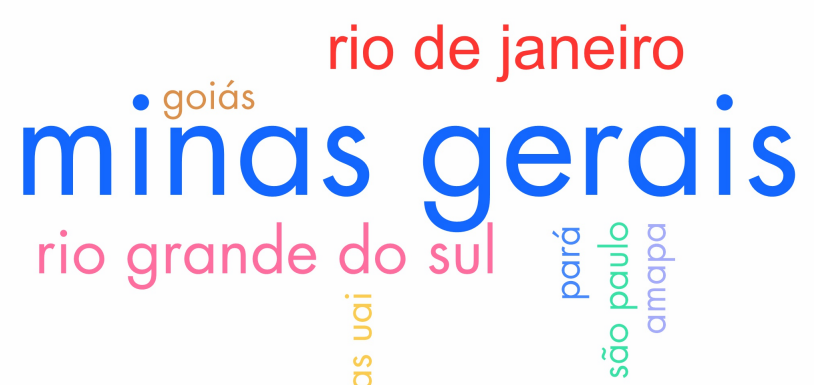

Figura 3: Word cloud gerada a partir da participação dos alunos no momento com o coordenador utilizando o Mentimeter. 
O aluno recebeu o link via chat e na lacuna colocaram o estado em que residem, dessa forma a imagem foi se alterando de forma interativa dando destaque em letra aumentada aos estados que se repetem e cores diferentes para cada estado. Neste caso, percebemos que Minas Gerais é o estado que possui mais alunos no curso (ingressantes daquele mês), seguido por Rio Grande do Sul e Rio de Janeiro, além dos demais citados.

É possível perceber a heterogeneidade em relação as regiões dos alunos neste curso, mostrando que o EAD é capaz de oportunizar o ingresso ao curso superior em qualquer parte do Brasil permitindo a troca e o intercâmbio de conhecimento e vivências acerca das regiões (MACHADO et al., 2020).

O último link, perguntava ao aluno os motivos que o levaram a ingressar no curso, neste momento, é interessante mencionar que as respostas são anônimas, portanto, os alunos se sentem à vontade para descrever os motivos reais que ingressaram no curso. $O$ recurso utilizado foi mais uma vez, o Word Cloud (Nuvem de palavras) (Figura 4).

\section{Por que estou fazendo este curso?}

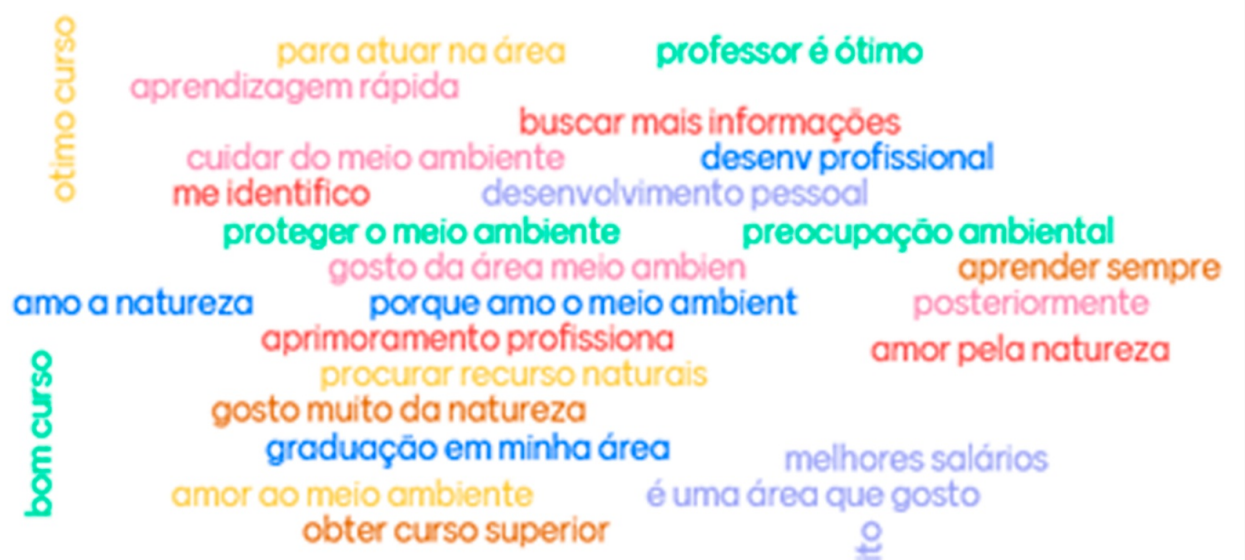

Figura 4: Word cloud gerada a partir da participação dos alunos no momento com o coorde-nador utilizando o Mentimeter.

Com esta nuvem de palavras é possível compreender os motivos que levaram os alunos a ingressar no curso de Gestão Ambiental que poderá nortear o corpo docente em relação aos conteúdos e estratégias de ensino aprendizagem para melhor desempenho no curso, buscando qualidade do ensino ofertado e a satisfação do aluno.

Neste novo cenário, com a paralização de aulas presenciais, o professor passa a ter um novo papel que não busca apenas transmitir conhecimentos, ele agora precisa conduzir o processo de aprendizagem do estudante de forma a desenvolver as suas capacidades (GUIMARÃES et al., 2020). O Mentimeter se mostrou uma ferramenta capaz de promover uma maior interação nas aulas virtuais.

\section{CONCLUSÃO}

É possível oportunizar e aprimorar o ensino remoto na Ead utilizando TDIC's como metodologia ativa como o Mentimeter que permitiu a ação colaborativa, participativa e dinâmica do aluno ao mesmo tempo que gera informações e subsídios sobre características do público-alvo possibilitando acompanhamento e melhoria do ensino.

Foi possível identificar características sociodemográficas e os motivos pelos quais os 
alunos ingressaram no curso de Gestão Ambiental da Faculdade Unida, gerando subsídios valiosos para avaliar tanto o curso, quanto o público-alvo.

Trabalhos como este potencializam o uso de metodologias ativas no ensino remoto, permitindo maior interação entre os alunos e fortalecendo a participação dos mesmos. O Mentimeter pode ser utilizado no ensino remoto contribuindo com os avanços da educação a distância cada vez mais necessária para a educação dando possibilidades diversas aos diferentes cenários de estudantes.

\section{CONFLITO DE INTERESSE}

Menciono não haver conflito de interesse para o manuscrito.

\section{REFERÊNCIAS}

DE MORAES, A. R.; MARTINS, G.; DOS ANJOS GENEROSO, B. Perfil dos ingressantes do curso de Tecnologia em Gestão Ambiental da Universidade Estadual de Mato Grosso do Sul-Unidade Universitária de Mundo Novo. IX Congresso Brasileiro de Gestão Ambiental. São Bernardo do Campo/ SP. 2018.

GIROTO, C. R. M.; POKER, R. B.; OMOTE, S. (Ed.). As tecnologias nas práticas pedagó-gicas inclusivas. Editora Oficina Universitária, 2012.

GUIMARÃES, T.; DE FREITAS, D. F.; FIGUEIREDO, F. J. B. A utilização do Mentimeter como Estratégia de Interação entre Professores e Estudantes nos Cursos de Saúde Integral EaD, v. 2, n. 1, p. 7-7, 2020.

JUNIOR, J. B. B. Aplicativos de interação em sala de aula: análise de três possibilidades pe-dagógicas com recursos digitais. Revista Cocar, v. 14, n. 30, 2020.

LEITE, B. Aprendizagem tecnológica ativa. Revista internacional de educação superior, v. 4, n. 3, p. 580-609, 2018.
MACHADO, K. G. W.; DOS SANTOS, P. K.; COSTA, C. S. As contribuições das tecnologias digitais para a internacionalização da Educação Superior em casa e a construção da cida-dania global. Revista Cocar, v. 14, n. 29, p. 700-722, 2020.

SANTOS, E; SILVA, M. O desenho didático interativo na Educação Online. Revista Ibero-americana de Educación, Madri, n. 49, p. 267-287, 2009

SCHNEIDER, E. M. et al. O uso das Tecnologias Digitais da Informação e Comunicação (TDIC): possibilidades para o ensino (não) presencial durante a pandemia covid-19. Revista Científica Educação, v. 4, n. 8, p. 1071-1090, 2020. 